\title{
A study on immunological response of leukocytes to ticks in cattle reared in sub-tropical region of Khyber Pakhtunkhwa Pakistan
}

\author{
Mian Saeed Sarwar ${ }^{1}$, Hazrat Ali ${ }^{1}$, Tahir Usman ${ }^{1}$, Naimat Ullah \\ $\mathrm{Khan}^{1 *}$, Hamayun Khan ${ }^{2}$, Imad Khan ${ }^{1}$, Mumtaz Ali Khan ${ }^{3}$ and Fazli \\ Rabbani ${ }^{1}$ \\ 1. College of Veterinary Sciences and Animal Husbandry, Abdul Wali Khan University Mardan-Pakistan \\ 2. Department of Animal Health, The University of Agriculture Peshawar-Pakistan \\ 3. Department of livestock and Dairy Development, Peshawar, KPK-Pakistan \\ *Corresponding author's email:naimatullahkhan19@yahoo.com; tahircau@gmail.com \\ Citation \\ Mian Saeed Sarwar, Hazrat Ali, Tahir Usman, Naimat Ullah Khan, Hamayun Khan, Imad Khan, Mumtaz Ali \\ Khan and Fazli Rabbani. A study on immunological response of leukocytes to ticks in cattle reared in sub- \\ tropical region of Khyber Pakhtunkhwa Pakistan. Pure and Applied Biology. Vol. 8, Issue 2, pp1655-1660. \\ http://dx.doi.org/10.19045/bspab.2019.80107
}

\begin{tabular}{llll}
\hline \hline Received: 18/02/2019 & Revised: 11/06/2019 & Accepted: 15/06/2019 & Online First: 18/06/2019 \\
\hline \hline
\end{tabular}

\section{Abstract}

Parasitic infestation in cattle is a common phenomenon in sub tropical conditions of Khyber Pakhtoonkhwa. The present study was designed to investigate the immune response of differential leukocytes count (lymphocytes, monocytes, eosinophils, basophils and neutrophils) against ticks in cattle under sub tropical conditions in the hilly areas of northern Khyber Pakhtunkhwa, Pakistan. A total of 40 tick infested cattle were divided into four age groups having 10 animals in each group i.e. G1 (3 years), G2 (4 years), G3 (5years) and G4 (6 years) were evaluated on the basis of different leukocyte count. The overall means counted in the present study were $3144.97 \pm 736.62 \mathrm{~mm}^{3}, 543.03 \pm 93.28 / \mathrm{mm}^{3}, 610.37 \pm 154.60 / \mathrm{mm}^{3}$, $51.4 \pm 7.38 \mathrm{~mm}^{3}$ and $32069.175 \pm 273.18 / \mathrm{mm}^{3}$ for total lymphocytes, monocytes, eosinophils, basophils and neutrophils respectively. There was non-significant association was recorded among different age groups on differential leukocytes count in tick infested cattle except on eosinophils count. As a result it was concluded that there is poor immune response of leukocytes to ticks except eosinophils in cattle.

Keywords: Basophils; Eosinophils; Immune; Lymphocytes; Neutrophils; Ticks

\section{Introduction}

Ticks are the blood feeding ecto-parasites having immense importance in animal health. They are different types of ticks i.e. hard and soft ticks. Both are acting a great threat to farmer community, particularly to cattle owner by transmitting different types of tick borne diseases such as babesioses, theileriosis etc. The neutrophils ratio is mostly lower than the lymphocytes ratio
$(\mathrm{N}: \mathrm{L})$ in case of cattle and sheep as compare to the other domestic species of the animals [1]. Goats older than three year of age have higher ratio of neutrophils $\&$ lymphocytes ratio than cattle and sheep but the goats having age less than three years have the same neutrophils and lymphocytes ratio as cattle and sheep [2]. In case of mild moderate inflammation in ruminants, there is frequent neutrophilia 
while normal neutrophils are seen in chronic stage of inflammation [3]. Neutrophilia associated with inflammation may or may not include a left shift, toxic changes, and hyperfibrinogenemia. In most of the cases the inflammatory neutrophilia has been observed in bacterial, viral, fungal, protozoal and parasitic infections affecting mammary gland, respiratory tract, gastrointestinal tract, liver, heart, urinary tract and central nervous system in goats, sheep and cattle [4].

Eosinophils are the most important leukocyte cells playing an important role in allergic reactions and parasitic infections. The eosinophilia has been recorded in different endoparasitic infections in goats [5], cattle and sheep [6]. However, it is not important that every parasitic infection must have the eosinophilia [7] although it showed that there was no increase in the peripheral eosinophils numbers when compared with controls to tick infested cattle.

Different studies showed that basophils also react like eosinophils (increase in number) with response to any allergic reactions and parasitic infestation i.e. cattle infested with ticks as reported by [7] and in goats experimentally infected with nematodes [8]. Cattle infected with flukes showed no increase in basophil numbers and sheep appear to be less likely to display basophilia than some other species [9].

Lymphocytes are also not common in case of large and small ruminants but some time it occurs in viral infection and in chronic inflammatory conditions. The most frequent cause of lymphopenia in ruminants is the corticosteroid induced stress response. Infection with bacteria, septicemia and other acute viral infection is also responsible for lymphopenia [10]
Stress, endotoxemia, acute and per acute inflammatory conditions due to any reasons are responsible for monocytosis [11]. Therefore the present study was conducted to determine the the immune response of different differential leukocytes count to ticks in cattle.

\section{Materials and methods}

\section{Study location}

A total of 40 tick infested cattle having age of three to six years were selected randomly for this study. These animals were than divided into four groups on the basis of their age i.e. G1 (3 years), G2 (4 years), G3 (5 years) and G4 (6 years) such as each group containing 10 animals.

\section{Sample collection}

The blood samples were collected from 40 animals and further experiments were carried out in Veterinary Research and Diagnostic Laboratory Balogram Swat. The tests for differential leukocytes (DLC) were carried out through slide method.

Statistical Analysis:

After collection of data, it was subjected to statistical method of analysis of variance as suggested by [12].

\section{Results}

\section{Lymphocytic count}

The overall lymphocyte count in tick infested cattle has been presented in (Table 1) where the overall means of lymphocytes were $3144.97 \pm 736.62 / \mathrm{mm}^{3}$. The animals in Group 4 have been showed higher lymphocytes count $3499.40 \pm 562.2 / \mathrm{mm}^{3}$ while cattle in Group 3 have been showed lower lymphocytes count $(2794.20 \pm 727.14 / \mathrm{mm} 3)$. The mean lymphocytes count of Group 1 and Group 2 were $3389.60 \pm 1253.27$ and $2896.70 \pm 403.97 / \mathrm{mm}^{3} \quad$ respectively. Analysis of variance showed that there was non-significant difference in lymphocytes count amongst different groups. 
Table 1. Lymphocytes count $\left(\mathrm{m} / \mathrm{mm}^{3}\right)$ in ticks infested cattle of different age groups

\begin{tabular}{|c|c|c|c|}
\hline Groups & Minimum & Maximum & Mean \pm S.D \\
\hline G1 & 1920 & 5648 & $3389.60 \pm 1253.27$ \\
\hline G2 & 2150 & 3500 & $2896.70 \pm 403.97$ \\
\hline G3 & 1980 & 3382 & $2794.20 \pm 727.14$ \\
\hline G4 & 2900 & 4550 & $3499.40 \pm 562.20$ \\
\hline Overall & 2237.5 & 4270.0 & $3144.97 \pm 736.64$ \\
\hline P-Value & & & $>0.05$ \\
\hline
\end{tabular}

\section{Monocytes count}

In the present study the overall mean of monocytes were also recorded $\left(492.025 \pm 93.39 / \mathrm{mm}^{3}\right)$ as presented by (Table 2). The current Study on monocytes indicates that the animals in Group 1 have been higher monocytes counts $\left(559.50 \pm 178.0 \mathrm{~mm}^{3}\right)$ while cattle in Group
3 have been lower monocytes counts $\left(425.00 \pm 50.0 \mathrm{~mm}^{3}\right)$. However, the mean monocytes count in G2 and G4 were $439.00 \pm 35.17$ and $544.60 \pm 109.50 / \mathrm{mm}^{3}$, respectively. Analysis of variance showed that there was non-significant difference in monocytes count among different animal groups.

Table 2. Monocytes count $\left(\mathrm{m} / \mathrm{mm}^{3}\right)$ in ticks infested cattle of different age groups

\begin{tabular}{|c|c|c|c|}
\hline Groups & Minimum & Maximum & Mean \pm S.D \\
\hline G1 & 360 & 888 & $559.50 \pm 178.9$ \\
\hline G2 & 328 & 502 & $439.00 \pm 35.17$ \\
\hline G3 & 305 & 698 & $425.00 \pm 50.00$ \\
\hline G4 & 422 & 728 & $544.60 \pm 109.50$ \\
\hline Overall & 353.75 & 704.0 & $492.025 \pm 93.39$ \\
\hline P-Value & & & $>0.05$ \\
\hline
\end{tabular}

\section{Eosinophils count}

The overall eosinophils counts of tick infested cattle under experiment are shown in (Table 3). The overall mean of eosinophils count was $623.20 . \pm 154.46 / \mathrm{mm}^{\mathrm{s}}$ recorded. The animals in Group 4 had been higher eosinophils count $678.00 \pm 144.35 / \mathrm{mm}^{3}$ than cattle in Group 2 where it was $564.00 \pm 109.64 / \mathrm{mm}^{3}$ whereas, the mean eosinophils count of $\mathrm{G} 1$ and G3 were $646.80 \pm 224.38$ and $604.00 \pm 139.48 \mathrm{~mm}^{3}$, respectively. Analysis of variance showed that there was highly significant difference in eosinophils count among different groups.

Table 3. Eosinophils count $\left(\mathrm{m} / \mathrm{mm}^{3}\right)$ in ticks infested cattle among different age groups

\begin{tabular}{|c|c|c|c|}
\hline Groups & Minimum & Maximum & Mean \pm S.D \\
\hline G1 & 480 & 774 & $664.80 \pm 224.38$ \\
\hline G2 & 526 & 600 & $564.00 \pm 109.64$ \\
\hline G3 & 545 & 673 & $604.00 \pm 139.48$ \\
\hline G4 & 610 & 735 & $678.00 \pm 144.35$ \\
\hline Overall & 540.25 & 695.50 & $623.20 \pm 154.46$ \\
\hline P-Value & & & $>0.05$ \\
\hline
\end{tabular}

\section{Basophils count}

The overall basophilic counts were recorded among different tick infested cattle under experiment as shown in (Table
4). The overall mean of basophiles was recorded $63.00 \pm 4.78 / \mathrm{mm}^{3}$. The animals in Group 4 have been showed higher basophilic value $71.00 \pm 3.60 / \mathrm{mm}^{3}$ while 
cattle in G3 had been shown lower basophilic value $52.00 \pm 3.60 / \mathrm{mm}^{3}$. The mean basophilic counts of G1 and G2 were $70.00 \pm 6.04$ and $59.00 \pm 5.91 / \mathrm{mm}^{3}$, respectively. According to the statistical analysis non-significant difference was recorded in basophils count among different age groups.

Table 4. Basophil count in $\mathrm{m} / \mathrm{mm}^{3}$ in ticks infested cattle among different age groups

\begin{tabular}{|c|c|c|c|}
\hline Groups & Minimum & Maximum & Mean \pm S.D \\
\hline G1 & 48 & 115 & $70 \pm 6.04$ \\
\hline G2 & 39 & 80 & $59 \pm 5.91$ \\
\hline G3 & 34 & 69 & $52 \pm 3.60$ \\
\hline G4 & 55 & 91 & $71 \pm 3.60$ \\
\hline Overall & 44 & 88.75 & $63.00 \pm 4.78$ \\
\hline P-Value & & & $>0.05$ \\
\hline
\end{tabular}

\section{Neutrophils count}

The overall mean of neutrophils count was $2069.18 \pm 273.18 / \mathrm{mm}^{3}$ (Table 5). The animals in Group1 had been higher neutrophils count $2110.20 \pm 652.2 / \mathrm{mm}^{3}$ than cattle in Group 2 where it was $2010.00 \pm 39.01 / \mathrm{mm}^{3}$. The mean neutrophil count of G3 and G4 were 2050.00 \pm 32.04 and $2106.50 \pm 369.50 / \mathrm{mm}^{3}$ respectively. Analysis of variance showed that there was no significant difference in neutrophils count among different age groups.

Table 5. Neutrophil count in $\mathbf{m} / \mathrm{mm}^{3}$ in ticks infested cattle of different age groups

\begin{tabular}{|c|c|c|c|}
\hline Groups & Minimum & Maximum & Mean \pm S.D \\
\hline G1 & 1355 & 3322 & $2110.2 \pm 652.20$ \\
\hline G2 & 1208 & 1866 & $2010.0 \pm 39.01$ \\
\hline G3 & 1165 & 2646 & $2050.0 \pm 32.04$ \\
\hline G4 & 1712 & 2725 & $2106.5 \pm 369.5$ \\
\hline Overall & 1360 & 2639 & $2069.17 \pm 273.187$ \\
\hline P-Value & & & $>0.05$ \\
\hline
\end{tabular}

\section{Discussion}

Different studies showed that there was slight decrease in the number of lymphocytes in ticks infested animals. Manak et al. [13] reported 4\% decline in lymphocytes count in tick infested cattle. Barker et al. [14] reported 5\% decrease in lymphocytes. Escudero and Resoso [15] reported $7.6 \%$ decline in total lymphocytes in tick infested cattle. Our results of monocyte count are in line with other studies in ticks loaded animals. Manak et al. [13] reported $6.3 \%$ decline in monocytes in cattle with ticks. Sandhu et al. [16] reported decrease in monocytes count ranging from 615 to 545 in tick infested cattle. Fisk and Jones [17] reported reduction in monocytes count ranging from 685 to 540. Barker et al. [14] also reported reduction in monocytes in those animals having ticks infested. In comparison with other researcher, Manak et al. [13] reported that eosinophils are reduced from 815 to 719 in all tick loaded animals. Dennis and Figg [18] reported reduction in eosinophils counts ranging from 715 to $635 / \mathrm{mm}^{3}$ in tick infested cattle. Trop, [19] also reported eosinophil reduction from 690 to $532 / \mathrm{mm}^{3}$ in cattle having ticks. Results of other researchers indicates that a little work has been done on the blood values of tick infested cattle however the data on tick infestation in the present study is in close agreement with previous research. Manak et al. [13] reported $7 \%$ decline in basophils count in animals having ticks. Sandhu et al. [16] reported that basophil reduced up to 66 from $71 \mathrm{~mm}^{3}$. Barker et al. [14] reported that basophils get reduced from 76 to 64 in 
tick infested cattle. The neutrophils count was lower reduces in those animals having ticks on their body. Sandhu et al. [16] reported that neutrophils get reduced from 3115 to $2070 / \mathrm{mm}^{3}$ in tick infested cattle. Fisk and Jones [17] also reported reduction in neutrophils count in animals having ticks. Barker et al. [14] reported that neutrophils get reduced from 2650 to $2090 / \mathrm{mm}^{3}$ in tick infested animals.

\section{Conclusion}

The results infer a slight effect of ticks on blood values in relations to different age group but losses may be extensive when ticks carry heamparasite. Proper use of acaricides drugs can control the burden of external parasite as well as economic losses and suitable media.

\section{Authors' contributions}

Conceived and designed the experiments: MS Sarwar \& NU Khan, Performed the experiments: H Ali \& I Khan, Analyzed the data: T Usman \& H Khan, Contributed materials/ analysis/ tools: F Rabbani, Wrote the paper: MA Khan.

\section{Acknowledgment}

We are thankful to the Veterinary Research Institute Balogram Swat, KPK, for their support and cooperation on provision of chemicals and technical support in the implementation of this study.

\section{References}

1. Taylor JA (2000). Leukocyte responses in ruminants. Lippincott Williams and Wilkins 39-404.

2. Holman HH \& Dew SM (1993). The blood picture of the goat. IV. Changes in coagulation times, platelet counts and leukocyte numbers associated with age. Res Vet Sci 6: 510 - 521.

3. Dore E, Fedteau \& Helie P (2003). Liver abscesses in Holstein dairy cattle. J Vet Inter Med 21: 853 - 856.

4. Adah MI, Otesile EB. \& Joshua RA (1993). Susceptibility of Nigerian West African dwarf and red Sokoto goats to a strain of Trypanosoma congolense. J Vet Para 47: 177 - 188.
5. Hayat CS, Hussain SM, Iqbal Z, Hayat B \& Akhtar M (1996). Effect of parasitic nematodes on haematology and productivity of sheep. Pak Vet J 16(2): 81-83.

6. Conboy GA \& Stromberg BE (1991). Hematology and clinical pathology of experimental Fascioloides magna infection in cattle and guinea pigs. Vet Para 40: 241-255.

7. Brown S, Barker J \& Askenase RW (1984). Bovine resistance to Amblyomma americanum ticks: an acquired immune response characterized by cutaneous basophil infiltrates. J Vet Para 16: 147-165.

8. Richard S \& Cabaret J (1993). Primary infection of kids with Teladorsagia circumcincta: susceptibility and blood constituents. Vet Para 47: 279-287.

9. Rothwell TL, Horsburgh B \& France MP (1994). Basophil leucocytes in responses to parasitic infection and some other stimuli in sheep. Res Vet Sci 56: 319-324.

10. Brun H, Gronstol $\mathrm{H}$ \& Hardeng $\mathrm{F}$ (1998). Experimental infection with Ehrlichia phagocytophila in cattle. $Z$ Vet B 45: 193-203.

11. Jain NC (1993). Essentials of Veterinary Hematology. Lea and Febiger, Philadelphia, pp 76-250.

12. Snedecor GW \& Cochron WG (1989). Statistical Methods $8^{\text {th }}$ Ed. Iowa State University, Press Ames Iowa, USA.

13. Manak NL, Gencer \& Ozkenlar Y (2006). Identification of tick species in realation to blood protozoan and their effect on blood cells. Cumhuriyet Universitesi Zara Ahmet Cuhadaroglu Meslek Yuksekokulu, Sivas, Turkey.

14. Barker RW, Hoch AL, Ralph G. Buckner \& Jakie A Hair (1991). Hematological changes in tick infested Jersey cattle. J Para 6: 10911098.

15. Escudero SH \& Resoso BB (1990). Life cycle of babesioses. Ind J Ani Sci 47: 720 . 
16. Sandhu GS, Grewal AS, Singh A, Kondal JK, Singh J \& Brar RS (1999). Experimental inoculation of parasitized tick tissue to young cattle. Department of Veterinary Pathology, College of Veterinary Sciences, Punjab Agriculture University Ludhiana, 141 004, India.

17. Fisk CH \& Jones RH (1998). Babesiosis and its effect on cattle. Aus Vet J 3: 89-90.
18. Dennis E \& Figg (2003). Clinical examination of blood of cattle. Department of Veterinary Tropical Disease, Faculty of Veterinary Sciences University of Pretoria Private Bag X04, Onsderstepoort 0110, South Africa Amer Vet Rev 30: 553.

19. Trop JA (1994). Blood picture and protozoan life cycle. Med. Hyg 4: 897902. 